\title{
How containment policy and medical service impact COVID-19 transmission: a cross-national comparison among China, the USA, and Sweden
}

\section{Beihang University \\ Daocheng Fu \\ Beihang University \\ Jinghua Wang \\ Beihang University}

Zhao Zhang ( $\sim$ zhaozhang@buaa.edu.cn )

\section{Research Article}

Keywords: COVID-19, epidemiology, containment

Posted Date: July 14th, 2021

DOI: https://doi.org/10.21203/rs.3.rs-663079/v1

License: (a) (i) This work is licensed under a Creative Commons Attribution 4.0 International License. Read Full License 


\section{Abstract}

As COVID-19 shows a heterogeneous spreading process globally, investigating factors associated with COVID-19 spreading among different countries will provide information for containment strategy and medical service decisions. A significant challenge for analyzing how these factors impact COVID-19 transmission is assessing key epidemiological parameters and how they change under different containment strategies across different nations. Focusing on finding factors that cause heterogeneous spreading results among different nations, we utilize a COVID-19 spread simulation model to estimate the core COVID-19 epidemiological parameters. We also analyze the correlation between these core COVID-19 epidemiological parameters and the times of publicly announced interventions among three specific countries, China (strictly containment), the USA (moderately control), and Sweden (only suggestion without containment). We find out that all three countries finally have similar and close to zero spreading rates in the third period of COVID-19 transmission. However, the three countries' recovery rate is different, leading to a distinct COVID-19 transmission process in the three countries. We further discover an epidemic fundamental diagram between COVID-19 "active infections" and "current patients." By combining the epidemic fundamental diagram with the COVID-19 spreading simulation model, we can quantify the country's COVID-19 medical capacity and make containment strategies. We propose hypothetical policies for Sweden and the USA and find out that these policies could decrease the confirmed infections by $90.5 \%$ and $42.6 \%$ and increase the recovery population by $78.6 \%$ and $87.5 \%$ for Sweden and the New York state of the USA. Our code is free open source, and our framework is easy to be applied to any country or region.

\section{Introduction}

During the outbreak and spreading of COVID-19, government containment policy and medical services are keys to constrain the spreading of this pandemic (1-5). In the initial outbreak period of COVID-19, there are three challenges for crisis mitigation: (1) Estimating central epidemiological parameters, such as the spreading rate and recovery rate of COVID-19, which can be used for short-term forecasting; (2) Implementing containment control policies such as city lockdown, close school and restaurant, selfisolation suggestion, and so on to restrict the contact between people; (3) Provide sufficient medical service to heal infected people.

In this paper, we first estimate the main epidemiological parameters of COVID-19 among three different countries, i.e., China, the USA, and Sweden. To achieve this goal, we build a discrete Susceptible-InfectedRecovered (SIR) model (6-10) that simulates the spreading process of COVID-19 for the three countries, respectively (Methods). Similar to the detection of changing point in the spread of COVID-19 in Germany (10), we also detect changing point and corresponding containment policy data in the three countries. What's more, we use the estimated parameters to the cross-national comparison of COVID-19 spreading among the three countries. The three countries' epidemiological parameters denote that all three countries have shallow spreading rates, except the recovery rates are different. China has the most considerable recovery rate, followed by the USA and Sweden. Such a difference in recovery rate denotes that the Chinese government provided better medical service to help people recover than the USA and Sweden. The recovery 
rate also helped China form a positive cycle to constrain this virus. China met the inflection point of COVID19 and constrained the second outbreak in April and May.

We investigate what caused the difference of recovery rate among the three countries. We find out a linear relationship between current patients and active infections; we name this relationship as epidemic fundamental diagram (EFD) as this relationship is very similar to the fundamental diagram (FD) of traffic flow $(11,12)$. The "stable state" part of the EFD represents the scenario when active infections are under the medical service capacity that current patients increase linearly with the rise of active infections. In comparison, the "unstable state" of the EFD denotes that current patients decline rapidly with the increase of active infection when active infections are over capacity. Both the USA and Sweden met the "unstable state of" their EFD while China only had the "stable state of" its EFD.

The cross-national comparison of COVID-19 points out the importance of medical service and heterogeneous space-time utilization in controlling the spreading process. Based on such outcomes, we make two hypothetical policies that assume that the government can provide the medical service continuously and limit the pandemic in a particular area, for the USA and Sweden, respectively. The simulation results demonstrate that if the Swedish government provides medical service to help cure infections continually, the inflection of active infections will appear in June. The total confirmed infected population is reduced to 41,912 with a $90.5 \%$ decrease, while the total recovered population is increased to 40,783 with a $78.6 \%$ increment. While if we take the lockdown policy to limit the pandemic in New York and provide satisfactory medical service all the time, the total confirmed population is reduced from 1,023,897 to 561,315 with a $42.6 \%$ decrease, and the total recovered population is increased from 142817 to 406873 with an $87.5 \%$ increase. Also, the active infections of the USA will appear in late May.

Our research is designed to investigate the effects of containment policy and medical service on COVID-19 spreading in different countries. In the following, we estimate the central COVID-19 epidemiological parameters among three different countries, followed by a cross-national comparison of these parameters. We then investigate what causes the difference of epidemiological parameters among China, the USA, and Sweden. Our research finally proposes Hypothetical policy for the USA and Sweden. Our method can be applied to other countries or regions. The code, data and figures are available on GitHub (13).

\section{Estimation Of Central Covid-19 Epidemiological Parameters}

\section{China}

China suffered from COVID-19 since December 2019 and began to take steps to constrain the spreading of the COVID-19 virus since January 2020. The spreading process is divided into three periods based on the E-Divisive with Medians (EDM, 14, 15) technology (Fig. 1A). The first period starts on Jan 23, 2020, and ends on Jan 31, 2020, followed by the second period, which begins on Feb 1, 2020, and ends on Feb 21, 2020. The last period starts on Feb 22, 2020, and ends at the end of the research time range. The main epidemiological parameters of China all follow a normal distribution in each period, as Fig S1 shows. 
When analyzing the spreading rate, effective spreading rate, and the recovery rate in Fig. $1 \mathrm{~A}$, we found out that the effective spreading rates in Period 1 fluctuate at a high level, ranging between 0.07 to 0.22 . In contrast, the effective spreading rate dramatically decreases in Period 2, i.e., the date boundary between Period 1 and Period 2 is the inflection point of effective spreading rate. At the end of Period 2, the effective spreading rate is close to zero and finally becomes negative.

It is important to note that the three periods' date boundary and control policy implementation dates agree. For instance, Wuhan municipal government locked down the city and closed train stations, airports, and highways on Jan 23 (the start date of Period 1) (16). Subsequently, the other 13 cities in Hubei province closed highways, train stations, airports and finally implemented a "lockdown" policy before Jan 31 (the end date of Period 1) (17). Further, Period 2 spans from Feb 1 (when all the provinces in the mainland of China have ordered "self-isolation" policy) to Feb 21 (when the first province in China lowered the emergent level from level 1 to level 3, Fig. 3) (18). It is worth mentioning that the control experience in January and February means a quick and effective containment policy ("lockdown" and "self-isolation") and a high level of medical service (high recovery rate in Fig. 1A). The fluctuation of the effective spreading rate in Period 1 demonstrates that the Chinese government spent some time (almost the length of Period 1) to learn effective containment policy to reduce the effective spreading rate. The medical service also takes time to rise to a high level.

In comparison, the dramatic decline of the effective rate and the rise of recovery rate in Period 2(Fig. 1A) verifies containment policy and medical service effectiveness. Since the effective spreading rate is minus 0 after Period 2, the active infected population decreases continually until late May. The active infected population is close to 0 , and the total confirmed infected population is become saturated (Fig. 1B). Fig. 1A also demonstrates that in June, the active infected population and effective spreading rate have a second rise, but benefit from the low active infected population after Period 2. This second rise is under control and over quickly. Generally speaking, Period 1 is the "response period" when the government responds to the epidemic and takes containment policy into effect. While Period 2 is the "recovery period" when the containment policy is taken into effect, and the effective spreading rate keeps decreasing. Period 3 is the "post-recovery period' when the recovery rate is higher than the spreading rate (effective spreading rate is near zero or negative) that the epidemic is under control. Like China, we will further divide the three periods in the USA and Sweden based on the effective spreading rate properties.

\section{The USA}

The effective spreading rate in Fig. 2 shows that the outbreak of COVID-19 in the USA happened in Jan 2020. Meanwhile, travel restriction policies have been implemented since February for suspending flights between the USA and China (19). Moreover, on Mar 20, travel restrictions have been implemented on many foreign nationals, including China, Iran, and many European countries. USA citizens were asked not to go abroad, and those who are abroad should "arrange for an immediate return to the USA" (20). Self-isolationrelated recommendations are first released on Mar 16 by the Center for Disease Control and Prevention (CDC). Mar 21, governors of New York, California, and other large states (21) had ordered the most business to close and for people to stay inside, with limited exceptions. 
Like the three periods in China, we also classify three distinct periods based on the USA's change of effective spreading rate (Fig. 2A). Period 1 ranges from Jan 22 to Mar 20, 2020, when the effective spreading rate fluctuates in a high range (Fig. 2A). On the contrary, Period 2 (Fig. 2A, Mar 20 to Apr 20) had a significant decrease in effective spreading rate, which may be attributed to the order of "self-isolation" related recommendations (22). The effective spreading rate in this period is close to 0 at the end. However, the inflection point did not appear (Fig. 2B). Unfortunately, the active infected population had a second rapid rise in October (Fig. 2B). Because the active infected population is high during that time range, the second outbreak rises rapidly.

\section{Sweden}

Like China and the USA, the spreading process is divided into three periods based on the evolution of effective spreading rate (Fig. 3A). The effective spreading rate fluctuated around 1.0 in Period 1 and continually decreased in Period 2. After Period 2, the effective spreading rate is close to zero. Like China and the USA, the three periods' date and control policy implementation date agreed. For instance, Period 1 spans from Jan 22 to Mar 10, when the Public Health Agency of Sweden (PHAS) advised everyone with respiratory infections, even mild cases, to refrain from social contacts where there is a risk of spreading the virus $(23,24)$. Period 2 starts on Mar 11 when the Swedish government passes a new law at the PHAS request, limiting freedom of assembly by banning all gatherings larger than 500 people, with the threat of fines and prison $(25,26)$. Then, Period 2 ends on Jun 30 , when the self-isolation recommendations contribute a lot to reduce the effective spreading rate. In late June, unlike the USA, the effective spreading rate in Sweden keeps continually reduce, and the active infected population grows slowly (Fig. 3B). However, the recovery rate also decreases in Periods 2 and 3 . Even the total recovered population rises; the Sweden government cannot make the effective spreading rate minus 0 . The inflection point never appears (Fig. 3B), and the outbreak of pandemic is not effectively controlled.

\section{Cross-national Comparison}

The transmission of the COVID-19 virus in the three countries shows a distinct process. We further compare the spreading rate, recovery rate, and effective spreading rate of these countries in Fig. 4 . The violin chart demonstrates no significant difference in COVID-19 spreading rate among these three countries, i.e., the spreading rates are all similar and keep low. The similarity of spreading rate among the three countries denotes that the three countries' containment policies function well. Among the three countries, Sweden has the most prominent fluctuation of spreading rate. The USA has the second-largest fluctuation of spreading rate, and China has the smallest fluctuation of spreading rate.

The comparison of the recovery rate among the three countries shows opposite property compared to the spreading rate. Fig. 4 shows that China's recovery rate is more significant than the USA's recovery rate, which is bigger than Sweden's recovery rate. Besides, China's recovery rate fluctuation is also more extensive than that of the USA and Sweden. The fluctuation of China's recovery rate agrees with the fact that the recovery rate is low in the response period and decreases in the recovery and post-recovery period. The recovery rate is an index that reflects medical service, such a difference in recovery rate denotes that 
the Chinese government provided better medical service to help people recover, compared to the USA and Sweden. Moreover, the higher recovery rate also helped China lower the effective spreading rate to less than 0 . The inflection point appeared in February, and the active infected population finally decreased.

All three countries had a second outbreak of COVID-19 that China had the second outbreak in late June, the USA and Sweden had the second outbreak in October. However, the second outbreak in China was already under control. The active infected population was reduced to almost 0 between August and December, a deficient level (Fig. 1B), so the second outbreak did not cause secondary damage. On the contrary, the second outbreak in the USA caused a significant rise in the active infected population (about 128,000 active infections per day after the second outbreak, Table S1) even though the effective spread rate is close to 0 (Fig. 2A). That is because the infected population and confirmed infected population in the USA is large, meaning a significant base of the infected population. Thus, a minimal effective spreading rate will cause a significant rise of the active infected population. Meanwhile, the medical service is not able to cure infected people. Thus, the rise of the USA's active infected population has never met an inflection point so far.

In Sweden, the government applied loose policies to constrain the pandemic. When the "self-isolation" and "banning all gatherings" related recommendations were taken into effect, the spreading rate began to decrease. The spreading rate keeps decreasing since Mar 20. Finally, the spreading rate was decreased close to 0 , recognized as the government has successfully prevented the spreading of COVID-19 in Sweden. However, the recovery rate is relatively low, so the active infections will keep growing at a low speed. We can see the growth of active infections becomes gentle from the beginning of July to the end of September in Fig. $3 \mathrm{~A}$, but the inflection point never appears. So at the beginning of October, since the weather becomes cold and people began to slack off on self-protect, the second rise of COVID-19 arrives, and because the active infections are still large, this second rise will be hard to handle. As a result, the second outbreak in Sweden caused a significant rise in the active infected population (about 3,400 active infections per day, Table S1)

The difference of time boundary and periods' duration in the three countries (Table 1) agree with the containment policies. China has the shortest duration of the response period ( 7 days) and recovery period (17 days). The USA has a more extended response period (30 days) and recovery (30days). Sweden implemented a slack containment policy, and it has a 17 days' duration of Period 1 and 110 days' duration of Period 2. It seems that Sweden has a better COVID-19 containment policy effect than the USA in the response period. However, Sweden takes a much longer time in Period 2 than the USA, which may be attributed to the recovery rate difference between Sweden and the USA (Fig. 4).

Based on the above discussions, it is clear that the three countries all applied containment polices to constrain the COVID-19 spreading rate effectively. The main difference in the three countries' spreading parameters is the recovery rate, which may explain the distinct difference in the three countries' medical services. Besides providing containment policies to constrain the virus spreading, the government should also provide adequate medical service to help the recovery of infected people, which can also reduce the active infected population and the effective spreading rate. 
Table 1. Cross-national comparison of periods duration

\begin{tabular}{|lllllll|}
\hline Nation & Start of Period & Start of Period & End of Period & $\begin{array}{l}\text { Data end } \\
\text { time }\end{array}$ & $\begin{array}{l}\text { Period } \\
1\end{array}$ & Period 2 \\
\hline China & Jan 23 & Jan 31 & Feb 17 & Dec 12 & 7 Days & 17 Days \\
\hline USA & Feb 20 & Mar 20 & Apr 20 & Dec 12 & $\begin{array}{l}30 \\
\text { Days }\end{array}$ & 30 Days \\
\hline Sweden & Feb 24 & Mar 10 & Jun 30 & Dec 12 & $\begin{array}{l}16 \\
\text { Days }\end{array}$ & $\begin{array}{l}110 \\
\text { Days }\end{array}$ \\
\hline
\end{tabular}

\section{Why the recovery rates in the USA and Sweden are small?}

As discussed above, the recovery rate is vital to reduce the active infections and finally eliminate the COVID-19 pandemic. This section will investigate why the USA and Sweden's recovery rates are much lower than China's and what we can do to prevent the pandemic's spreading.

The Public Health Agency of Sweden (PHAS) provides the intensive hospitalizations data of Sweden (27), which shows that the current patient of COVID-19 from July to October is relatively small in Sweden (Fig S3). When the active infections and the current patients in Period 1 and Period 2 are plotted together in Fig. $5 \mathrm{~A}$, we can discover that the scatters can be naturally clustered into two parts (blue scatters and red scatters). In the left part of Fig. 5A, the current patients increase with active infections since the medical service are adequate. While in the right part, the current patients decrease with the increase of daily active infections, which means the medical services are not enough and the newly increased intensive infections cannot be hospitalized, so the recovery rate eventually decreases in Period 3 (Fig 3A).

The two-part phenomenon discussed in Fig. 5A is analogous to the fundamental diagram (FD) in traffic flow (Fig. 5B): when the density of road is under a critical density, the road can be operated under its designed capacity, traffic flow will increase with the density, that is, the "stable flow" in the left part (Fig. $5 B)$. Moreover, when the density exceeds the critical density, the road will be congested, the roads' capacity also dropped, and the flow will decrease, and that is the "unstable flow" in the right part (Fig. 5B). So if we want to effectively control the COVID pandemic, ensuring active infections in the "stable flow" part is critical.

We further analyze Sweden's control policies, as Cubeloadan et al. (29) shows that the medical servicerelated policies were applied well before April. However, such policies were decreased after April when the effective spreading rate is small, and the active infections grow slow. One possible explanation is that the Sweden government did not provide sufficient medical services for infections. In fact, by the research of Kavaliunas et al. (30), the main overarching aims of the Sweden government are "a) to reduce the mortality and the morbidity in the population, and $b$ ) to minimize various negative consequences for individuals and society." That is to say, the Sweden government tried to make a balance between constraining COVID-19 and reducing social and individual cost. Thus, the government did not devote all its resources to supply 
medical service cure the infections. Fig. 3B demonstrates that the active infections are still growing, making the second rise in October harder to control than the first one.

On the contrary, the Chinese government provides sufficient medical services for infections. We got the current patients from the National Health Commission of the People's Republic of China (4) and compared the data with active infections, as Fig. $5 \mathrm{C}$ shows. In Fig. 5C, the current patients grow as active infections grow, and when the active infections decrease, the current patients also decrease. So different from Sweden, the current patients did not show a decrement while the active infections are still growing. This phenomenon verifies that in China, the current patients and active infections are always kept in the left "stable state" of EFD. Thus, infections can always get needed medical service and the recovery rate can keep relatively high.

Fig. $5 \mathrm{D}$ shows the scatter of active infections and current patients in the USA, which present apparent different parts in this figure. Interestingly, there are two EFDs in Period 1 and Period 2 in the USA rather than one single EFD in Sweden. The first EFD in Fig.5D is the EFD for New York between Feb 2020 and Jun 20,2020, while the second EFD is for Florida between Jun 21, 2020, and Sep 21, 2020. Such difference is attributed to the heterogeneous distribution of the COVID-19 pandemic in the USA. It firstly happens in New York and then spread to Florida and other states (Fig. S4).

The two EFDs in Fig. 5D presents that the current patients decrease while the active infections are still growing from April to late June and from July to late September. The decline of current patients means that the active infections bypassed the "capacity" of the EFD in New York and Florida, respectively. Thus, some patients may not get medical service during these two periods. For this reason, the USA's recovery rate cannot keep at a high level, and the inflections of active infections will not appear. Because there is not sufficient medical service, both states meet the unstable status of their EFD. Finally, in October, all these states have a second rise, and current patients have the third rise, like Fig. 2B shows.

Fig. 5D demonstrate two COVID-19 spreading features in the USA: a) some of the patients cannot get adequate medical service; $b$ ) there exists a time-space heterogeneous of the spreading process of COVID19 in the USA. The COVID-19 first outbreak in one place, like New York state, and then spread to other place, like Florida state. In China, COVID-19 also shows heterogeneous, but the lockdown policies helped prevent the pandemic quickly spread out of Hubei. Fig. 6 shows that most of the active infections were limited in Huber $(74 \%)$ on one exact day, outer Huber, the active infections are relatively small. Moreover, thanks to the heterogeneous, the other provinces can quickly control their pandemic and share the redundant medical service to help Hubei cure infections (31). According to the research of (32), the medical service in Hubei has a shortage at the beginning of the pandemic. So, other provinces' help is just critical for China to control the pandemic fully. Otherwise, the pandemic will, just like Sweden, have a second rise later, and Hubei will not control the pandemic, finally, cause much cost.

\section{Hypothetical policy for the USA and Sweden}


The above analysis verifies the critical difference between Sweden and China is the medical service. To ensure the active infections in Sweden is always in the left "stable state" part of the EFD, the Swedish government should provide sufficient medical service to keep the capacity of the current patients is always larger than the real current patients. Thus, we assume that the Swadesh government's policy is: "providing satisfactory medical service that the recovery rate at its high level" (Fig. 7A). Based on this policy, we simulated the SIR model in Sweden, and Fig 7B demonstrates that the total confirmed population is reduced from 437,379 to 41,912 , with a $90.5 \%$ decrease (Fig. 7B). In comparison, the total recovered population is increased from 8,727 to 40,783 with a $78.6 \%$ increment (Fig. 7C). Finally, the inflection point of active infections will appear in May without a second rise (Fig. 7D). This hypothetical control policy will significantly control the pandemic in Sweden.

As for the USA, it is crucial to prevent COVID-19 from spreading around the whole country by establishing lockdown policy and concentrate all other states' medical service to help severe pandemic areas. So we make two hypothetical containment polices like this: (1) implement lockdown policy to limit pandemic outbreak in New York", then (2) provide more medical service to keep the recovery rate at its level in May

(Fig. 8A). The simulation result in Fig. 8B demonstrates that the total confirmed infected population is reduced from $1,023,897$ to 561,315 with a $42.6 \%$ decrease. The total recovered population is increased from 142,817 to 406,873 with an $87.5 \%$ increase (Fig. $8 \mathrm{C}$ ). The inflection point of active infections will appear in May (Fig. 8D). However, from Fig. 8D, we can see that the active infection is still too high when the second rise comes, and it will be hard to control it in the second rise. So for the USA, providing sufficient medical service for infections is of critical importance. Another good thing is that the lockdown policy help other states control the pandemic quickly and can share their redundant medical service to help New York.

\section{Discussion}

We presented a SIR simulation-based approach to investigate the impact of containment policy and medical service on COVID-19 spreading in different countries. Using the example of the COVID-19 outbreak and transmission in China, the USA, and Sweden, we apply this approach to infer the core epidemiological parameters and different periods of the COVID-19 pandemic. We found an exact comparison of spreading rate, recovery rate, and effective spreading rate among the three countries (Fig. 4). It is concluded that: (1) the spreading rate of the three countries are similar and low during the transmission process; (2) the recovery rate of the three counties is significantly different, which (3) leads to a significant difference in effective spreading rate and active infected population.

Our research indicates that medical service is the key to keep a high recovery rate to constrain the spreading of COVID-19. We further find an epidemic fundamental diagram (EFD) between active infections and current patients in Sweden. This EFD describes that the current patients linearly increase with active infections in the first "stable" stage. It linearly decreases with the increase of active infections in the second "unstable" stage. The boundary of the two stages determines the "capacity" of the national medical service. Further analysis reveals that the Sweden government did not provide sufficient medical 
service for infections after April. Thus, the "capacity" was constrained at a low level, and the recovery rate also keeps low. Our research also finds out similar EFD between active infections and current patients in the USA, except that the USA has more than one EFD, attributed to the heterogeneity of COVID-19 spreading in the USA. Unlike Sweden and the US, China only has the "stable" stage of a EFD, which states that China has good medical services. It is worth noting that China also has the same problem as the USA, i.e., China has a heterogeneous distribution of COVID-19 infections among its 31 provinces (Fig. 6). The medical resources in the very early outbreak period in Wuhan are very scanty. Due to the Wuhan and Hubei province lockdown, the other provinces have time to prepare for the coming transmission of COVID-19, which constrains the virus well. Meanwhile, the other provinces supported Hubei and sent medical resources, including doctors, nurses, and medical equipment. Hubei had sufficient medical sources and kept a slow rise of recovery rate (Fig. 1A) and finally constrains the spreading of COVID-19 in Hubei and China.

Our framework can be easily applied to other countries and enables future prediction of COVID-19 transmission. For other countries, the government and academic administrations need to record accurate data, such as daily active infections, recovery population, and current patients, to build the proposed SIR model and plan hypothetical containment policies. The framework presented here can find critical time boundaries, the EFD, and medical resources' current capacity to constrain COVID-19 or other pandemics. The EFD reveals the fundamental relationship between medical service and pandemic infections; once the active infections exceed this country's medical capacity, the medical resources cannot heal the infected people. Thus the current patients decrease. Such phenomena are very similar to the traffic flow theory. When traffic flow exceeds the road capacity, the traffic flow will dramatically decline and results in a "gridlock" situation that no vehicle can move on the road. The model outputs state that the USA and Sweden's active infections bypass their capacity. The government did not supply sufficient medical resources (capacity), which explains why both countries' active infections keep rising, even the spreading rate in the USA and Sweden are meager. Both countries are in the "unstable" stage and stuck in a vicious circle, making a second outbreak or third outbreak quickly happen.

Based on our model outputs, we build hypothetical policies for the USA and Sweden. The recovery rates are kept at a high level (Fig. 7A and Fig. 8A), and the government did not lower the medical service. The simulation of the SIR model in Sweden demonstrates that the total confirmed infections population was reduced from 437,379 to 41,912 (90.5\% reduction), and the total recovered population is increased from 8,727 to 40,783 ( $78.6 \%$ rise). The inflection point appeared in May. Similar results are obtained for the USA. The total confirmed infections population in New York was reduced from 1,023,897 to 561,315 (42.6\% reduction), and the total recovered population in New York was increased from 42,817 to 406,873 (87.5\% rise). The inflection point also appeared in May.

In conclusion, our modeling approach reveals and quantifies the epidemic fundamental diagram of national COVID-19 pandemics and medical service's capacity. Our analysis highlights the importance of supplying sufficient medical resources. It also stresses the importance of containment policy such as lockdown policy for big countries like China. The lockdown policy cut off the human mobility between the 
first pandemic outbreak and another safe area and ensures other areas have time to deal with the coming pandemic, and supply medical resources to the first pandemic outbreak area. The lockdown policy in Wuhan city and Hubei province helps China build a virtuous cycle for pandemic prevention.

\section{Methods}

We build a model to measure control policies' strength based on the simple Susceptible-Infected-Recovered (SIR) model (6-9). In our model, we divide the total population $N$ into three compartments: Susceptible compartment $(S)$, Infected compartment $(I)$, and Recovered compartment $(R)$. A susceptible individual will become infected at a spreading rate if he is contacted with an infected individual. Besides, an infected person can be recovered at a recovery rate. Our model uses differential equations to dynamically simulate the spreading process of COVID-19 in different countries or regions. More details of the model can be found in the SI.

\section{References}

1. Dong E, Du H, Gardner L. An interactive web-based dashboard to track COVID-19 in real-time. Lancet Inf Dis. 20(5):533-534. DOI: 10.1016/S1473-3099(20)30120-1

2. Johns Hopkins University, COVID-19 Data Repository by the Center for Systems Science and Engineering (CSSE) (2020); https://github.com/CSSEGISandData/COVID-19

3. "Folkhälsomyndigheten - Antal fall av covid-19 i Sverige - data till och med föregående dag publiceras varje tisdag-fredag kl. 14:00 " (2020, December 10). Retrieved December 10, 2020, from: https://experience.arcgis.com/experience/09f821667ce64bf7be6f9f87457ed9aa/page/page_0/

4. Epidemic notification from National Health Commission of the People's Republic of China (2020, Dec 10). Retrieved Dec 10, 2020, from: http://www.nhc.gov.cn/xcs/yqtb/list_gzbd.shtml

5. The COVID Tracking Project (2020, Dec 10). Retrieved Dec 10, 2020, from: https://covidtracking.com/data.

6. Hethcote, H. W. . (1989). Three Basic Epidemiological Models. Springer Berlin Heidelberg.

7. H. Hethcote, The mathematics of infectious diseases. SIAM Rev. 42, 599-653 (2020). doi:10.1137/S0036144500371907

8. Anderson, J. S. , Lampl, I. , Reichova, I. , Carandini, M. , \& Ferster, D. . (2000). Stimulus dependence of two-state fluctuations of membrane potential in cat visual cortex. Nature Neuroscience, 3(6), 617-621.

9. Maier, B. F. , \& Dirk, B. . (2020). Effective containment explains subexponential growth in recent confirmed covid-19 cases in china. Science (New York, N.Y.), 2020, volume 368, 742-746.

10. Dehning, J. , Zierenberg, J. , Spitzner, F. P. , Wibral, M. , \& Priesemann, V. . (2020). Inferring change points in the spread of covid-19 reveals the effectiveness of interventions. Science, 369(6500), eabb9789.

11. B.D. Greenshields, A study of highway capacity, in: Proceedings of the Highway Rersearch Board, vol. 14, Washington 1935, pp. 448-477. 
12. Kerner, \& Boris, S. . (2009). Introduction to modern traffic flow theory and control II. Physics Today, 10.1007/978-3-642-02605-8(3), 53.

13. Fdarco,

MedicalServiceAndPandemic(2021); https://github.com/Fdarco/MedicalServiceAndPandemic

14. James, N. A. , Kejariwal, A. , \& Matteson, D. S. . (2016). Leveraging Cloud Data to Mitigate User Experience from "Breaking Bad". 2016 IEEE International Conference on Big Data (Big Data). IEEE.

15. James, BreakoutDetection R package. (2020) from: https://github.com/twitter/BreakoutDetection

16. Hubei Province People's Government. Jan 21 2020. “Circular of the Hubei Provincial People's Government on strengthening the prevention and control of pneumonia caused by New Coronavirus infection". Archived from the original on Feb 5 2020. Retrieved Jan 22

2020.from: http://www.hubei.gov.cn/xxgk/gsgg/202001/t20200122_2013895.shtml

17. Caixin. Jan 29 2020. "All 31 provinces in the mainland of China launched the first level response to public health emergencies"..Archived from the original on Feb 2 2020. Retrieved Feb 22020.

from: https://china.caixin.com/2020-01-29/101509411.html

18. World Health Organization. Feb 26 2020. "WHO Director-General's opening remarks at the mission briefing on COVID-19 - Feb 26 2020". from: https://www.who.int/director-

general/speeches/detail/who-director-general-s-opening-remarks-at-the-mission-briefing-on-covid-19-26-february-2020

19. Koenig, David; Bussewitz, Cathy; Pisani, Joseph (Jan 31, 2020). "Delta, American and United suspend flights between US, China". Associated Press. Retrieved May 30,

2020.from: https://apnews.com/article/7a165f73821fdd44e321a38be005886c

20. Wong, Edward (Mar 19, 2020). "As Pandemic Grows, U.S. Warns Americans Not to Travel Abroad”. The New York Times. ISSN 0362-4331. Retrieved May 20, 2020,

from: https://www.nytimes.com/2020/03/19/us/politics/coronavirus-state-department-travel.html

21. The Wall Street Journal. 2020. “A Guide to State Coronavirus Lockdowns”, Retrieved Mar 21, 2020. from: https://www.wsj.com/articles/a-state-by-state-guide-to-coronavirus-lockdowns-11584749351? mod=theme_coronavirus-ribbon

22. Sheikh, Knvul (Mar 16, 2020). “No More Than 10 People in One Place, Trump Said. But Why?”. The New York Times. ISSN 0362-4331. Retrieved Apr 15, 2020.

from: https://www.nytimes.com/2020/03/19/us/politics/coronavirus-social-distance-crowd-size.html

23. Sverige(in Swedish). 2020, “Flera tecken på samhällsspridning av covid-19”. Retrieved 10 March 2020. from: https://www.folkhalsomyndigheten.se/nyheter-och-press/nyhetsarkiv/2020/mars/flera-teckenpa-samhallsspridning-av-covid-19-i-sverige/

24. Stefansson, Klara (10 March 2020)."Risken för coronaspridning i Sverige höjs till 'mycket hög'".SVT Nyheter (in Swedish). from: https://www.svt.se/nyheter/inrikes/risken-for-coronaspridning-i-sverigehojs-till-mycket-hog

25. V. Nyheter, S. (11 March 2020)."Regeringen stoppar stora möten". SVT Nyheter (in Swedish). Retrieved 11 March 2020. from: https://www.svt.se/nyheter/snabbkollen/regeringen-stoppar-stora-moten 
26. Filip Persson, Stefan Bjarnefors. 2020. "Klart: Inga evenemang med fler än 500 besökare" [Clear: No events with more than 500 visitors]. Göteborgs-Posten (in Swedish). 11 March 2020.

from: https://www.gp.se/nyheter/sverige/klart-inga-evenemang-med-fler-\%C3\%A4n-500bes\%C3\%B6kare-1.25224161

27. Irrational Software AB, (2020), "Covid-19 in Sweden: patients in intensive care", from: https://www.covid19insweden.com/en/healthcare.html\#intensivecare

28. Wu, X. , Michalopoulos, P. , \& Liu, H. X. . (2010). Stochasticity of freeway operational capacity and chance-constrained ramp metering. Transportation Research Part C Emerging Technologies, 18(5), 741-756.

29. Cubeloadan, Spaastm, Vladimir Skokan1 et al. (2021) COVID-19 pandemic in Sweden \# public healthcare system. Retrieved Feb 25, 2021. from: https://en.wikipedia.iwiki.eu.org/wiki/COVID19_pandemic_in_Sweden\#Public_healthcare_system

30. Kavaliunas, A. , Ocaya, P. , Mumper, J. , Lindfeldt, I. , \& Kyhlstedt, M. . (0). Swedish policy analysis for covid-19. Social Science Electronic Publishing.

31. Li Yan. (2020). Some medical assistance teams leave Hubei Province. Xinhua. from: http://www.ecns.cn/hd/2020-03-18/detail-ifzunmih1238434.shtml

32. Zhang, Z. , Yao, W. , Wang, Y. , Long, C. , \& Xinmiao, F. U. . (2020). Wuhan and Hubei covid-19 mortality analysis reveals the critical role of timely supply of medical resources. Journal of Infection, 81( 1), 147-178

33. Scipy probplot package. (2020). from: https://docs.scipy.org/doc/scipy/reference/generated/scipy.stats.probplot.html

\section{Figures}




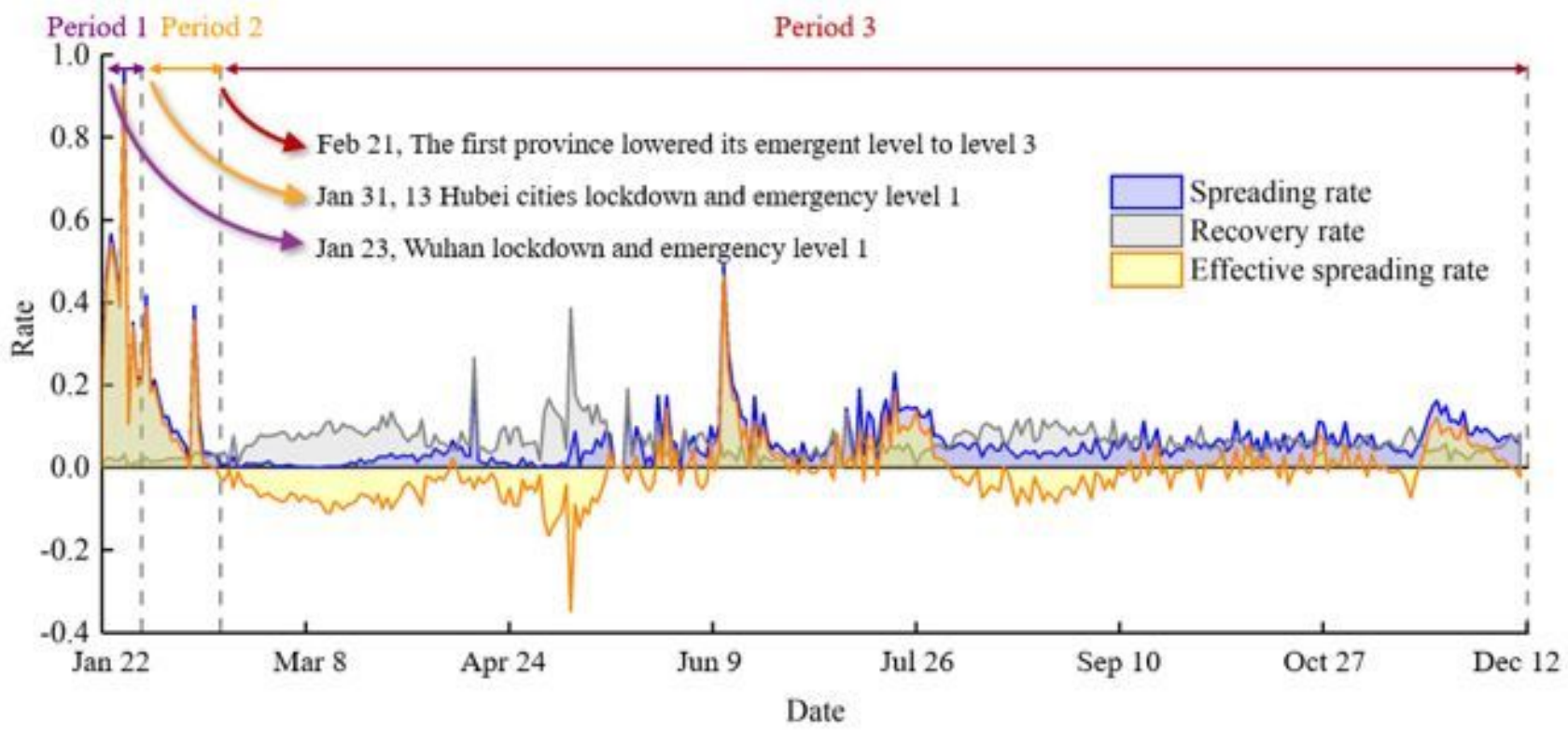

A

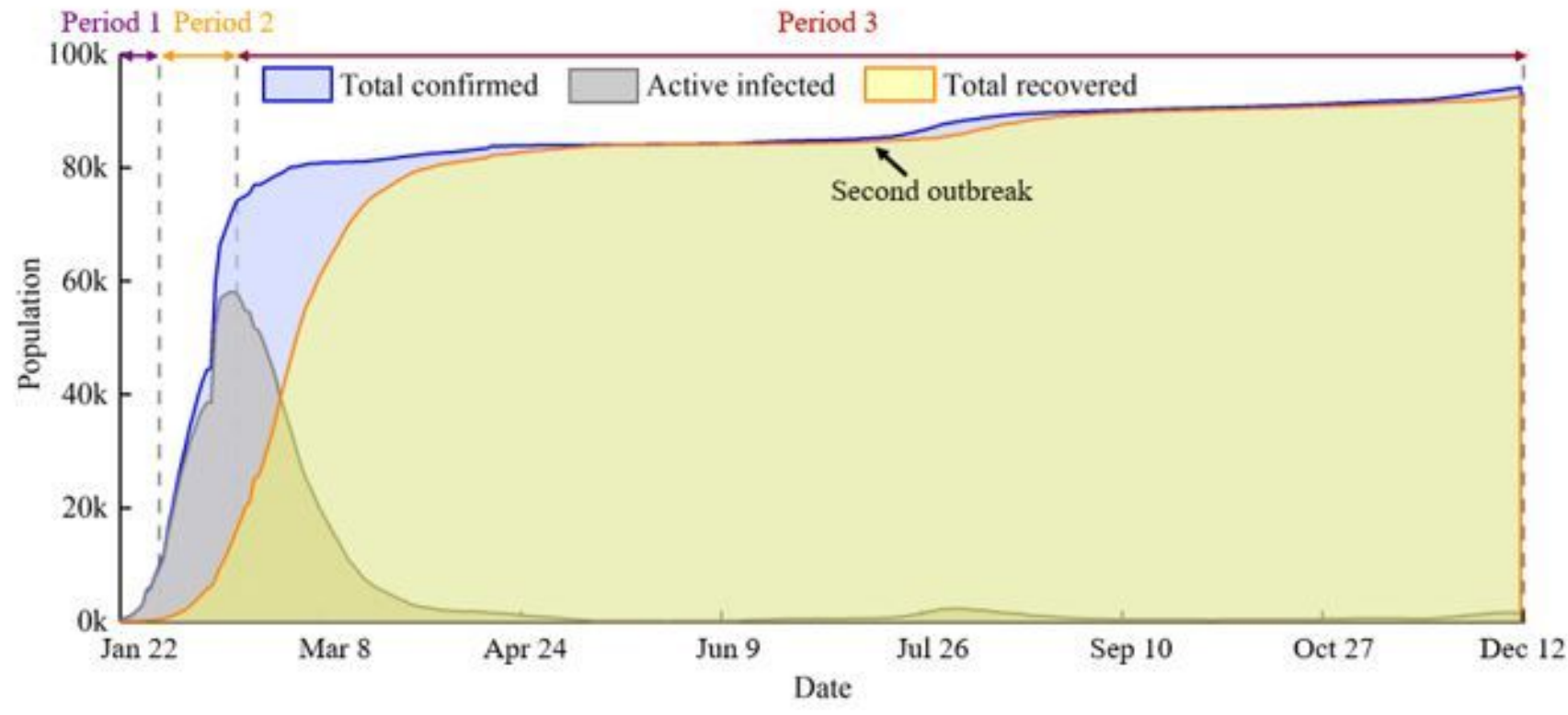

B

\section{Figure 1}

Spreading process of COVID-19 in China (A: main epidemiological parameters: the spreading rate and effective spreading rate are both high in Period 1, while they both decreases in Period 2; In Period 3, the spreading rate is near-ly 0 and the effective spreading rate is minus 0 ; the recovery rate keeps raising in the whole time range; $\mathrm{B}$ : the evolu-tion of total confirmed infected population, active infected population and total recovered population: the active infect-ed population raises in Period 1 and 2, and it decreases after Period 2; the total recovered population raises in the whole time range, and the total confirmed population 
reached saturation and stable state after Period 2; there is a short time the second rise of the active infected population in July but the Chinese government quickly controlled it.
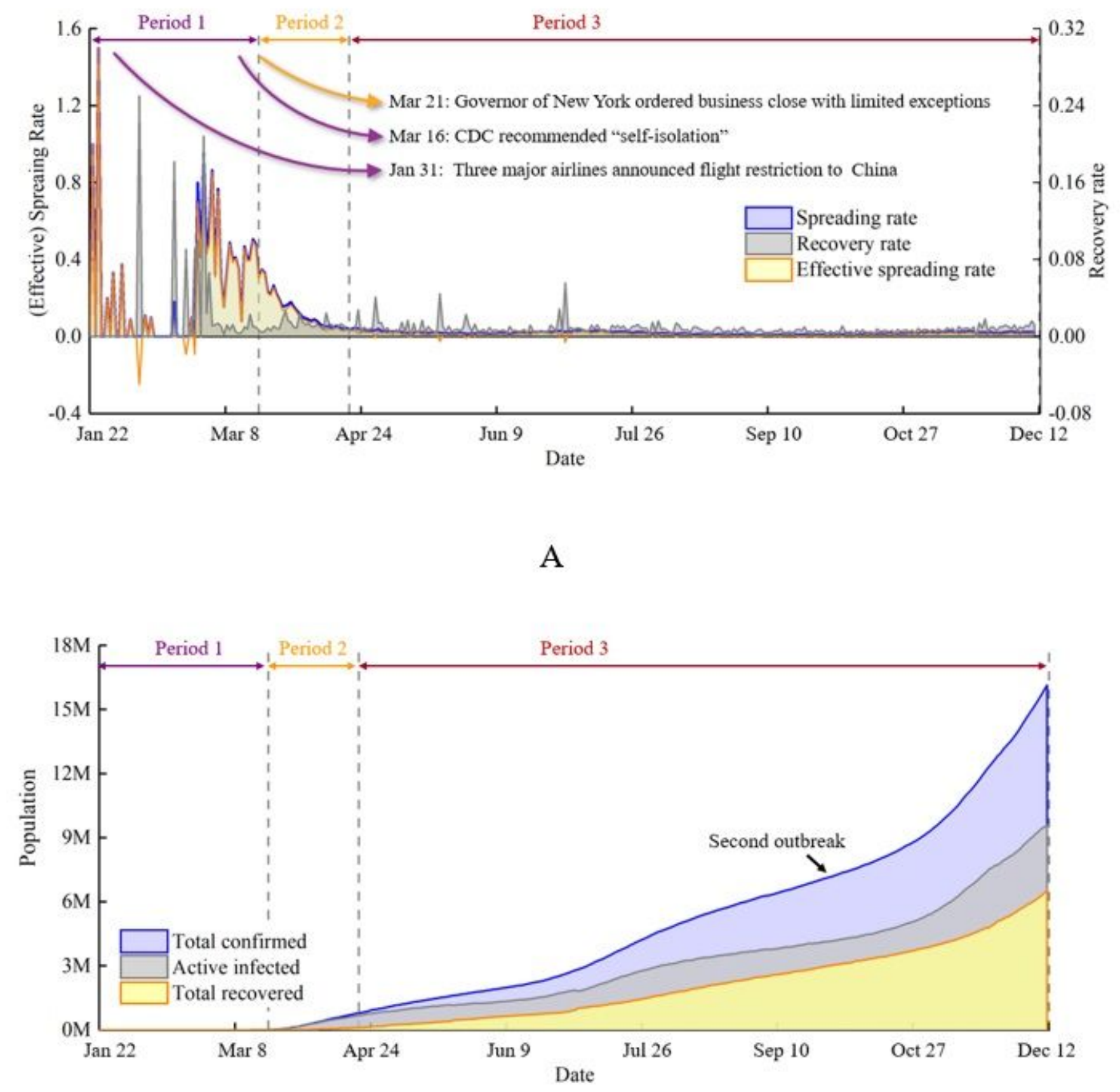

B

Figure 2

Spreading process of COVID-19 in the USA (A: main epidemiological parameters: the effective spreading rate in Period 1 is high, while the effective spreading rate decreases in Period 2; However, the effective spreading rate in Period 2 is not reduced to 0 , leading to a continuous increasing of active infected 
population and total confirmed pop-ulation; B: the evolution of total confirmed infected population, active infected population and total recovered popula-tion: the active infected population and total confirmed infections both keep growing even the total recovered popula-tion raises, which is attributed to the immense amount of active infected population and the none negative effective spreading rate in the whole time range.

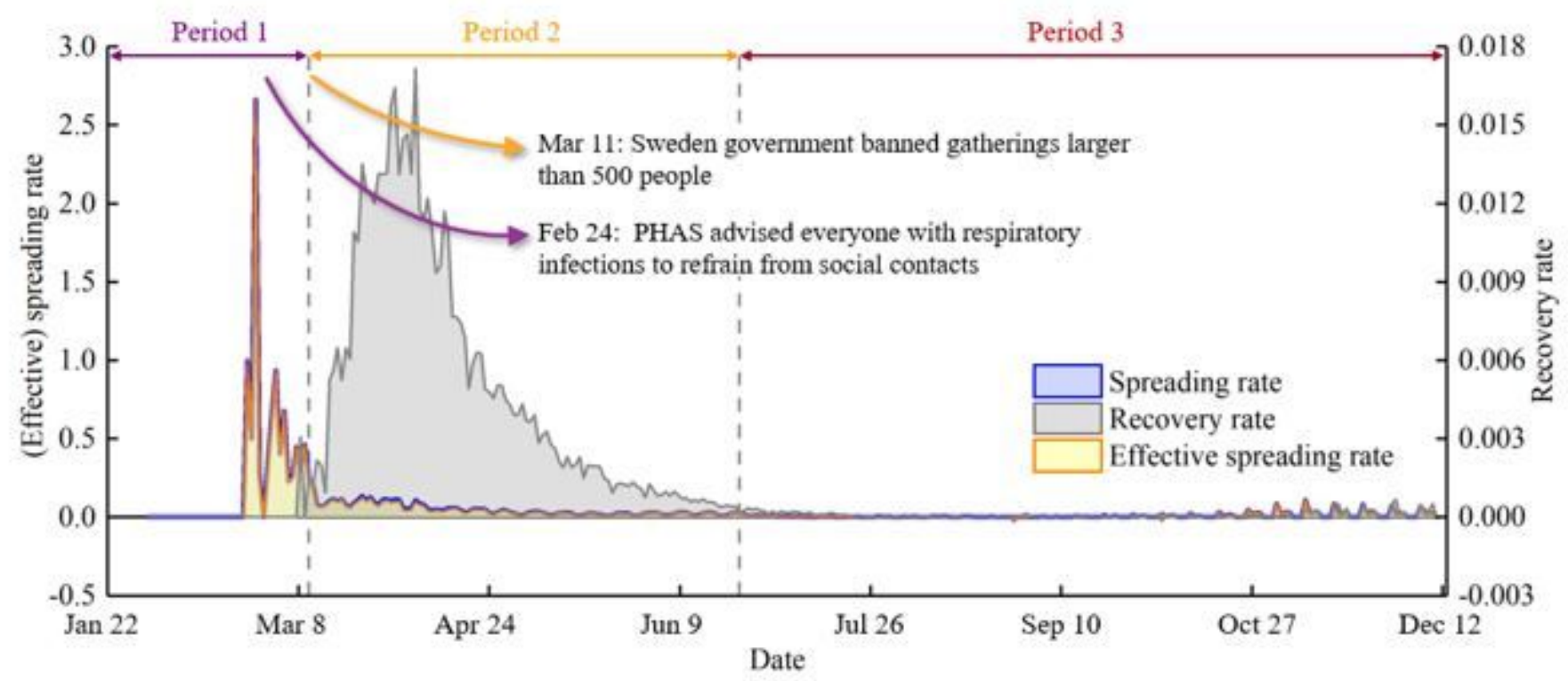

A

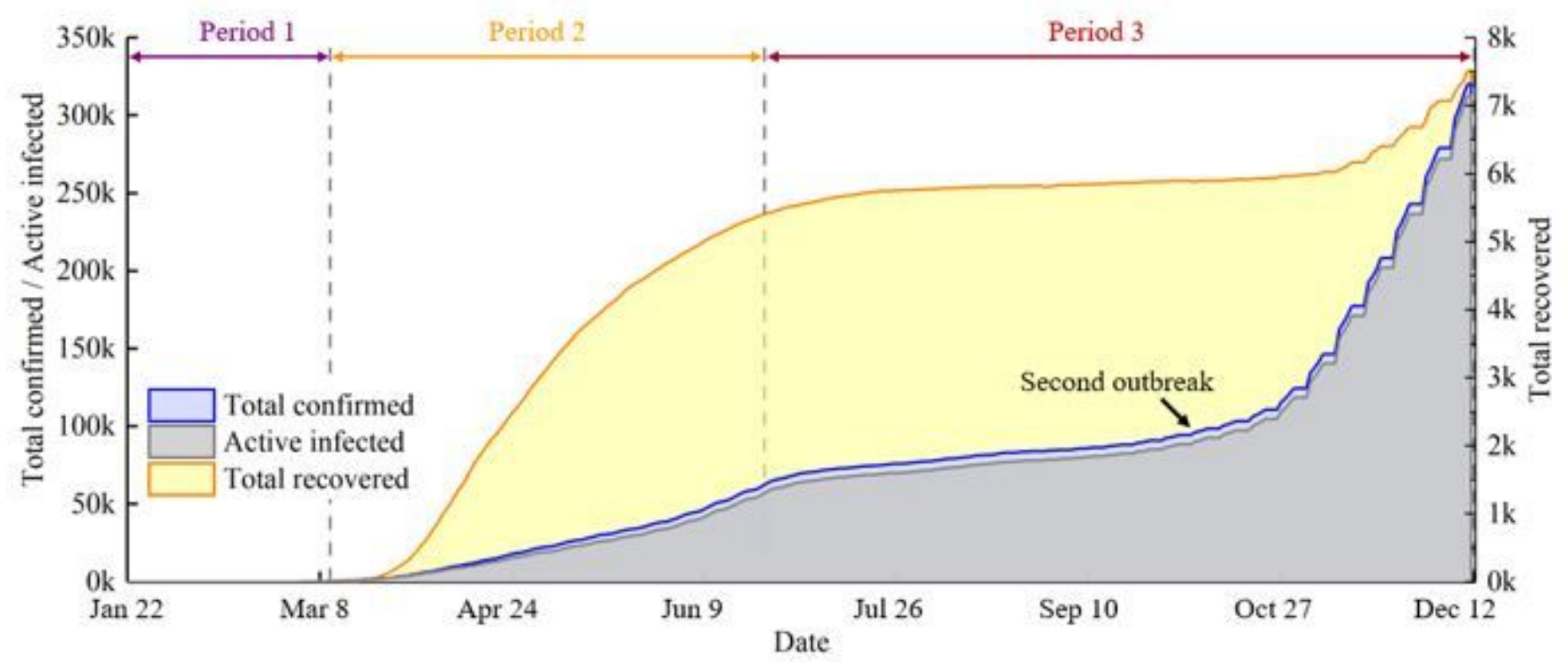

B

\section{Figure 3}

Spreading process of COVID-19 in Sweden (A: main epidemiological parameters: the effective spreading rate in Period 1 is high, while the effective spreading rate decreases in Period 2; However, the effective 
spreading rate in Period 2 is not reduced to minus 0 , leading to a continuous increasing of active infected population and total con-firmed population; $\mathrm{B}$ : the evolution of total confirmed infected population, active infected population and total recov-ered population: the active infected population and total confirmed infections both keep growing before Jun 30, 2020. Like the US, the effective spreading rate in Sweden keeps continually reduce, but the active infected population also grows.

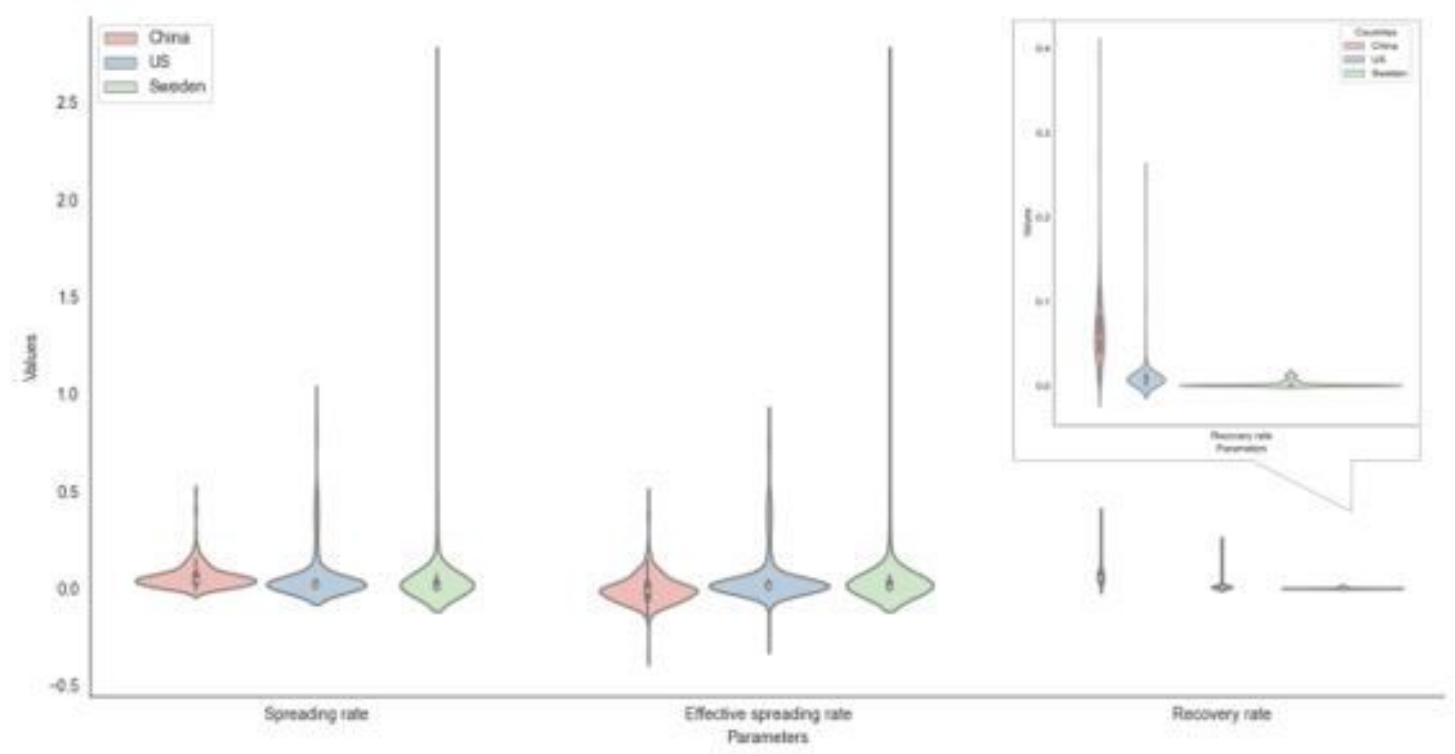

\section{Figure 4}

Spreading rate, recovery rate, and effective spreading rate in China, the USA, and Sweden. 


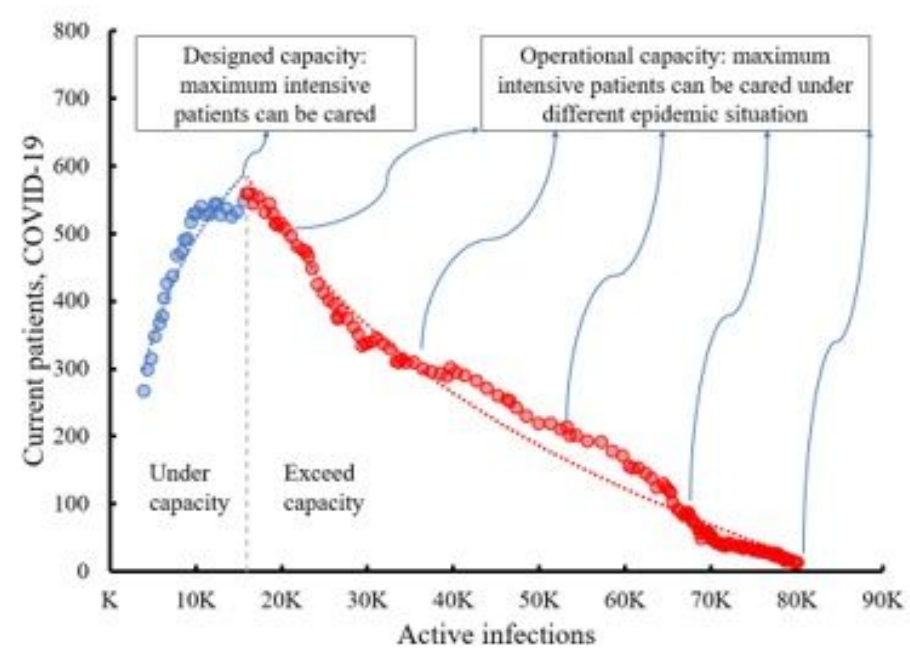

A

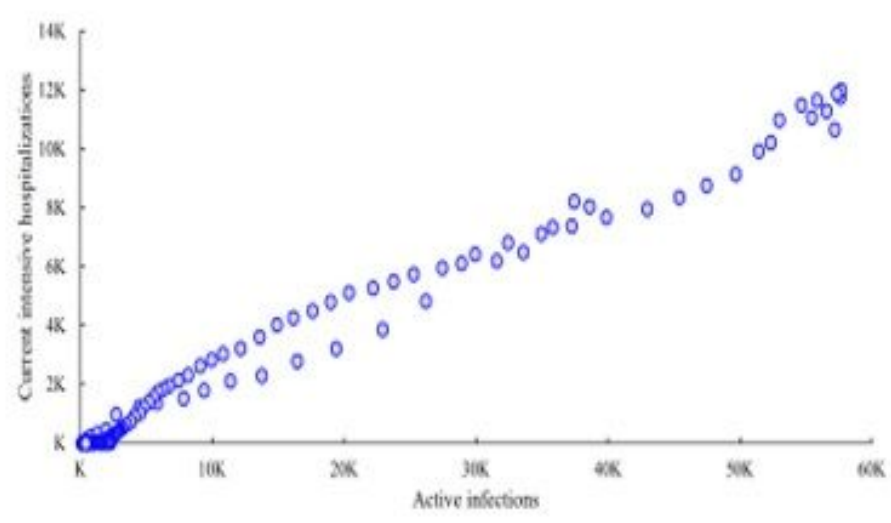

$\mathrm{C}$

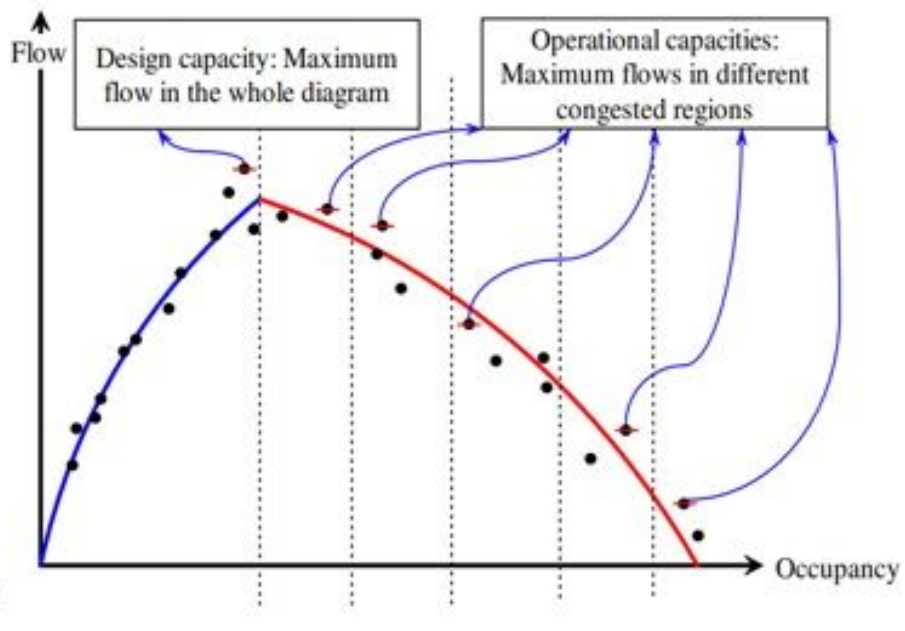

B

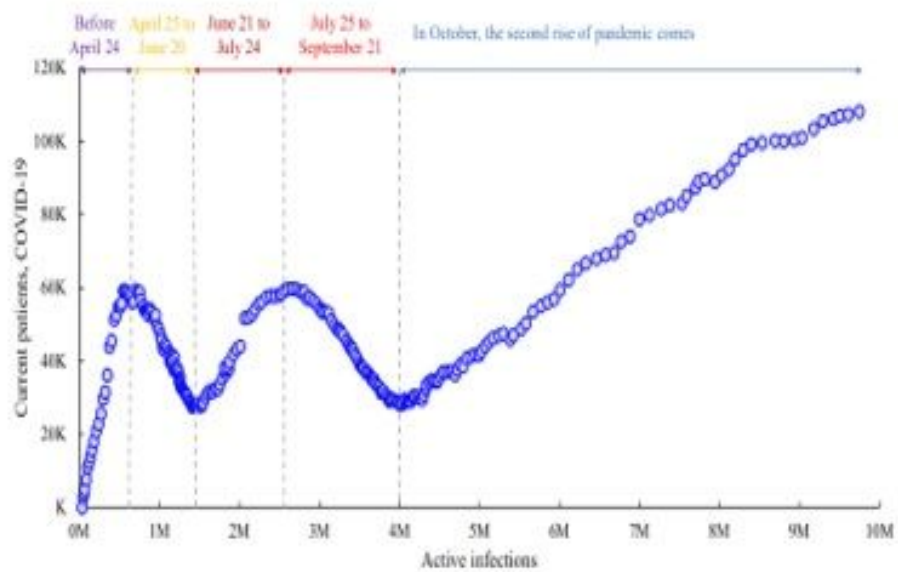

$\mathrm{D}$

\section{Figure 5}

Current patients and active infections (A: epidemic fundamental diagram; B: traffic flow fundamental diagram (28); C: the current patients and active infections in China; D: the current patients of COVID-19 in the USA.) 


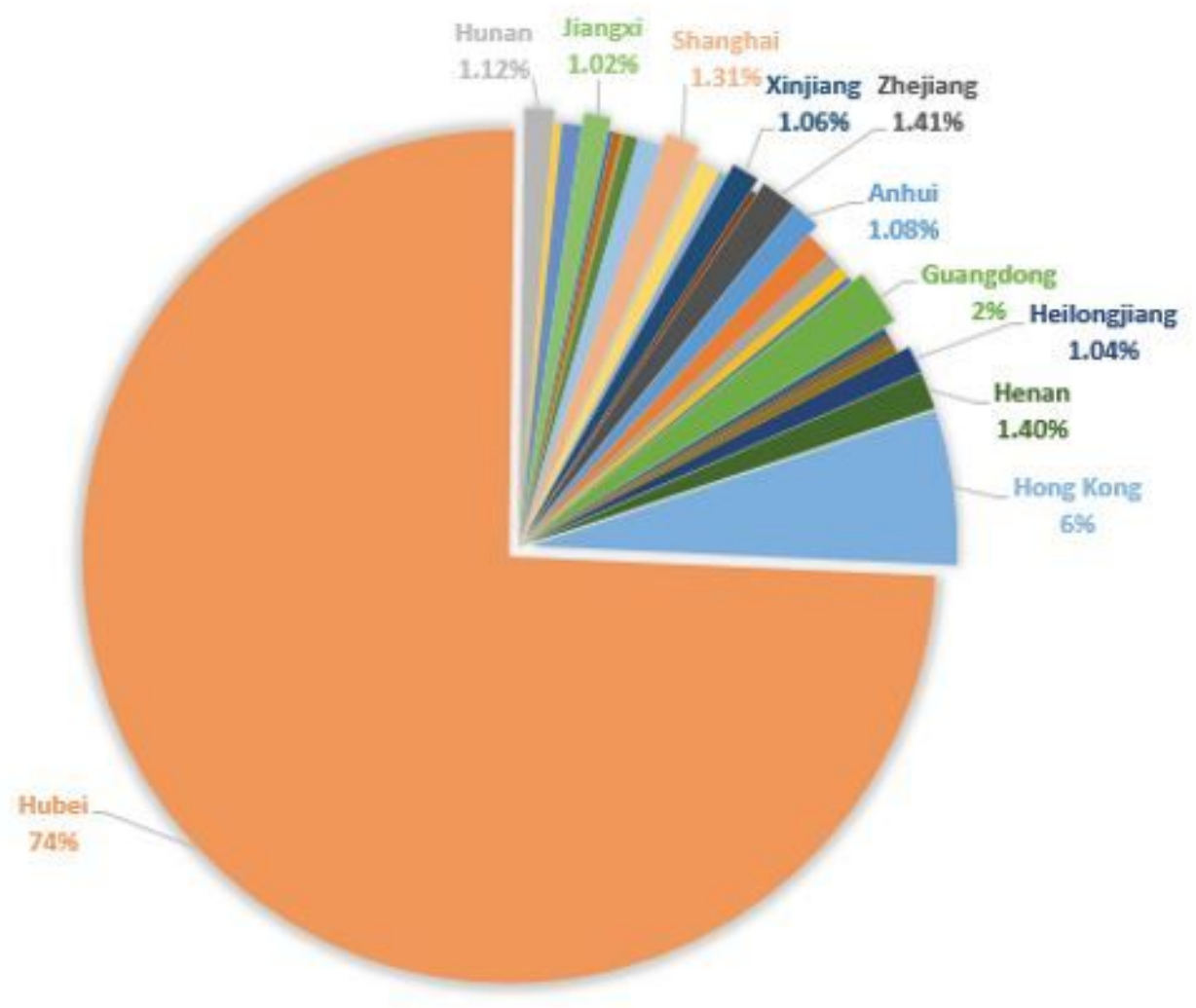

Figure 6

The proportion of total confirmed infections of different provinces in China on Feb 24, 2020 


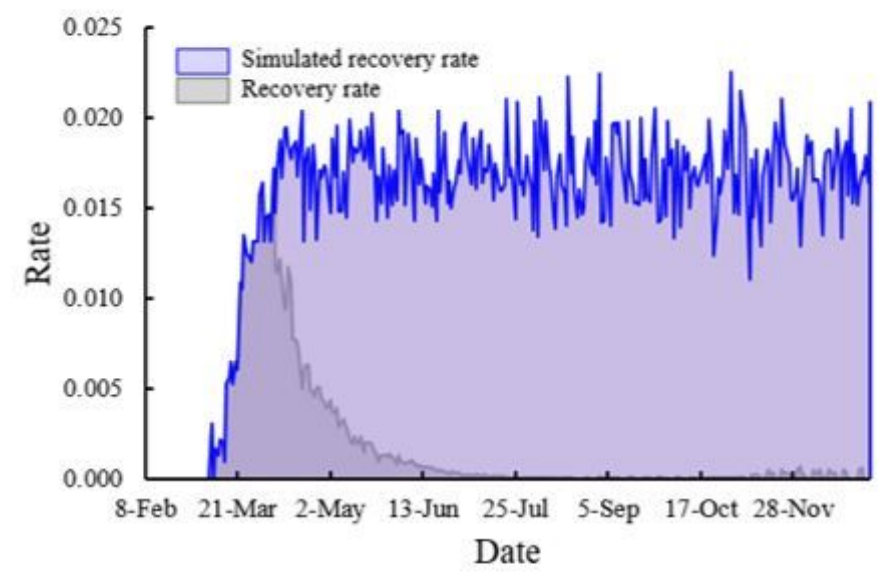

A

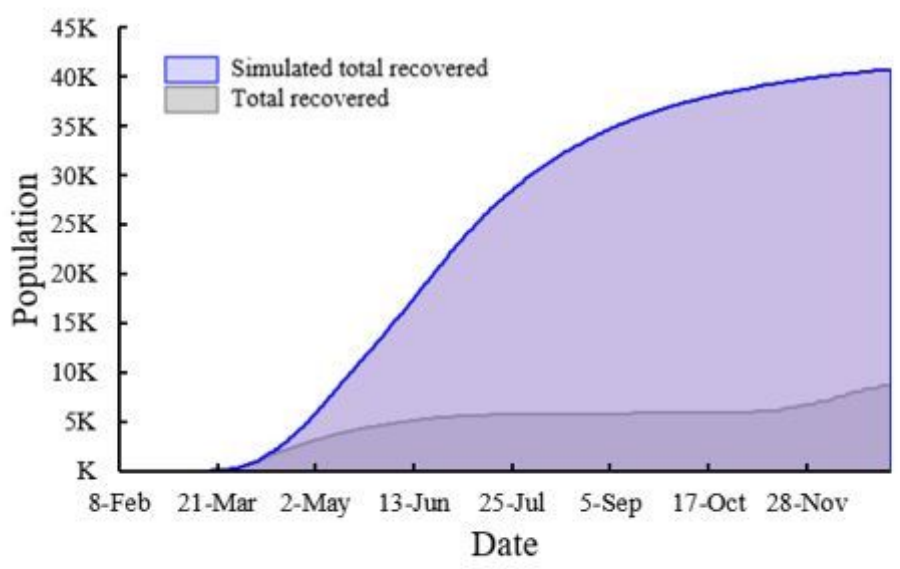

$\mathrm{C}$

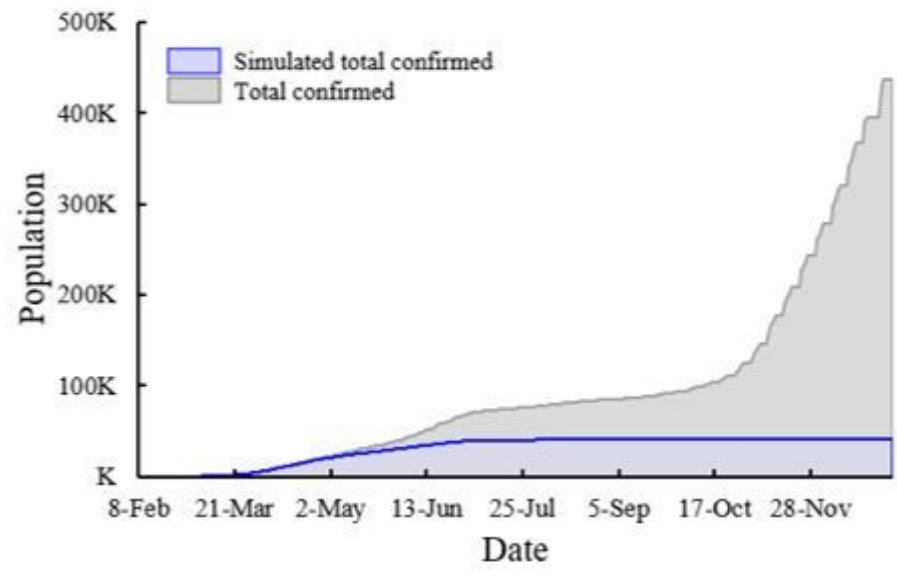

B

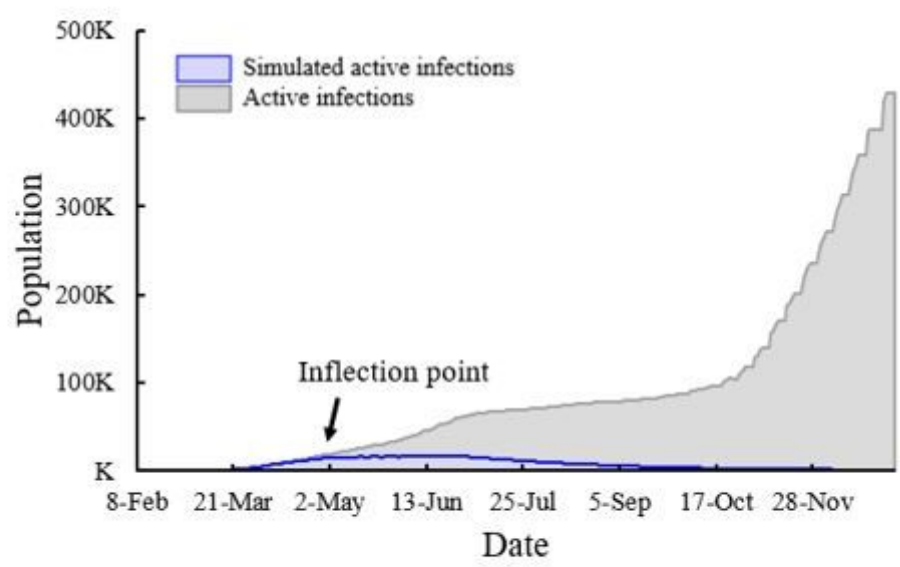

$\mathrm{D}$

\section{Figure 7}

Simulated results of hypothetical containment policy in Sweden. (A: the recovery rate; B: the total confirmed infec-tions; $\mathrm{C}$ : the total recovered population; $\mathrm{D}$ : the active infections.) 


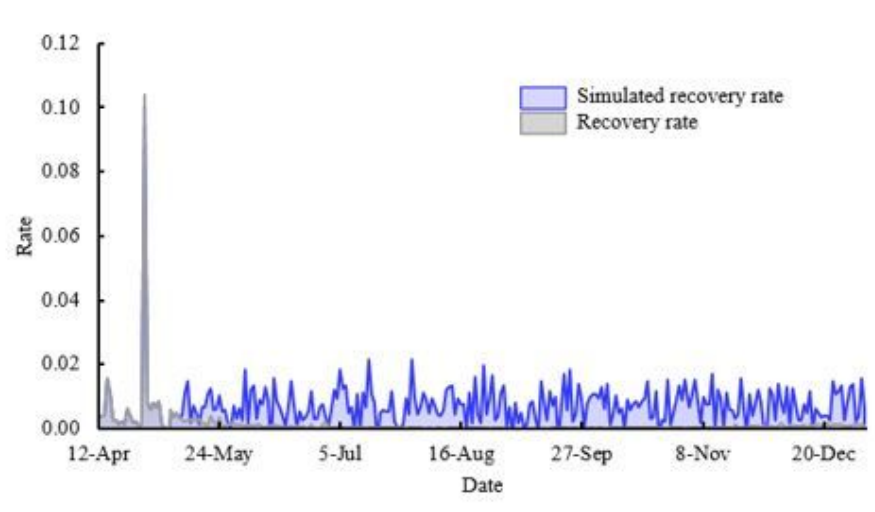

A

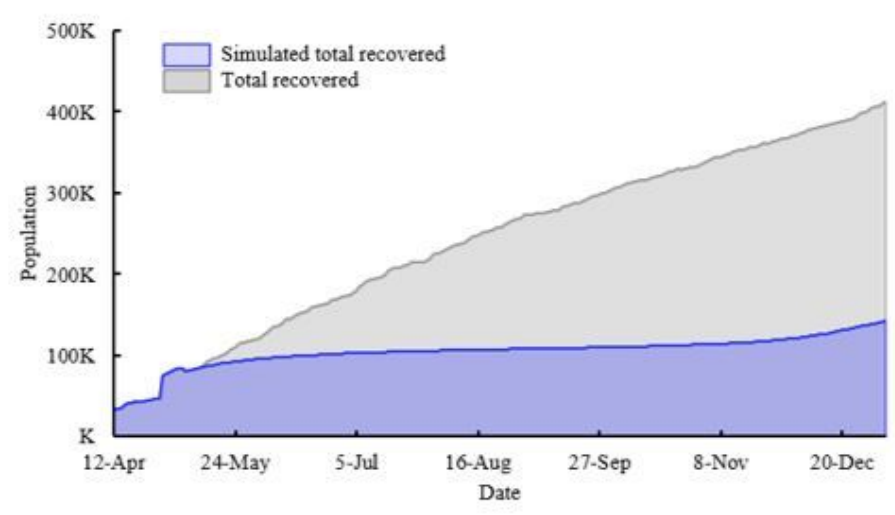

C

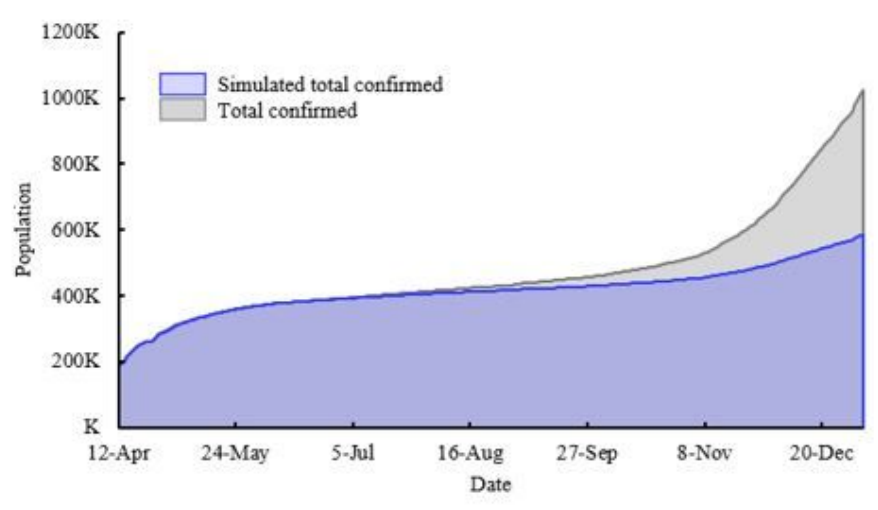

B

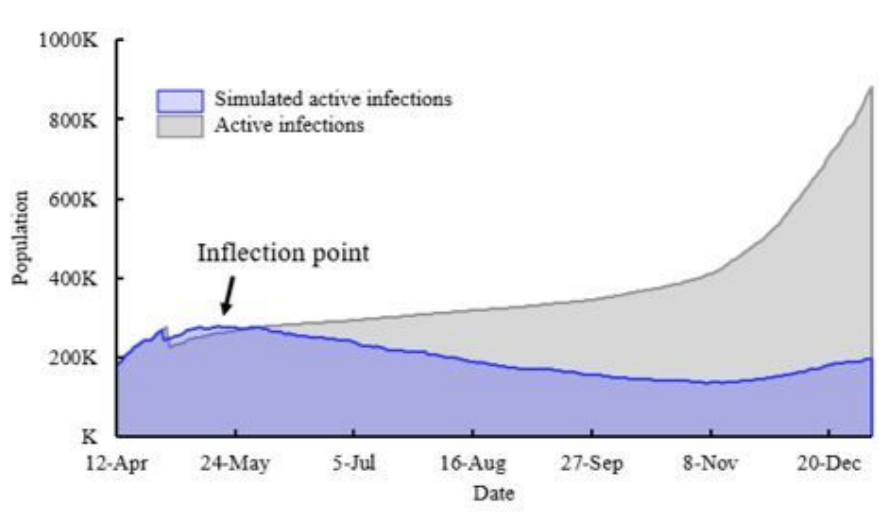

$\mathrm{D}$

\section{Figure 8}

Simulated results of hypothetical containment policy in Sweden. (A: the recovery rate; $B$ : the active infections; C: total confirmed population; D: the total recovered population.)

\section{Supplementary Files}

This is a list of supplementary files associated with this preprint. Click to download.

- Sl.docx 